\title{
Induction of Apoptosis by Saussurea lappa and Pharbitis nil on AGS Gastric Cancer Cells
}

\author{
Seong-Gyu Ko, ${ }^{*, a, b}$ Seung-Hee KoH,${ }^{c}$ Chan-Yong Jun, ${ }^{c}$ Chang-Gyu NAM, ${ }^{d}$ Hyun-Su BAE, ${ }^{e}$ and \\ Min-Kyu SHIN ${ }^{e}$ \\ ${ }^{a}$ Department of Tumor Biology, Cancer Research Institute, College of Medicine, Seoul National University; 28, Yongon- \\ dong, Chongno-gu, Seoul, Korea: ${ }^{b}$ Department of Internal Medicine, College of Oriental Medicine, Sangji University; \\ 283, Woosan-dong, Wonju-si, Korea: ${ }^{c}$ Department of Internal Medicine, College of Oriental Medicine, Kyungwon \\ University; 117, Yong-dong, Jung-gu, Incheon, Korea: ${ }^{d}$ Department of Internal Medicine, College of Oriental Medicine, \\ Semyung University; 21-1, Sinweol-dong, Jecheon-si, Korea: and ${ }^{e}$ Department of Physiology, College of Oriental \\ Medicine, Kyunghee University; 1, Hoegi-dong, Dongdaemun-gu, Seoul, Korea.
}

Received April 26, 2004; accepted July 13, 2004

We performed this study to understand the molecular basis underlying the antitumor effects of Saussurea lappa, Pharbitis nil, Plantago asiatica and Taraxacum mongolicum, which have been used for herbal medicinal treatments against cancers in East Asia. We analyzed the effects of these medicinal herbs on proliferation and on expression of cell growth/apoptosis related molecules, with using an AGS gastric cancer cell line. The treatments of Saussurea lappa and Pharbitis nil dramatically reduced cell viabilities in a dose and time-dependent manner, but Plantago asiatica and Taraxacum mongolicum didn't. FACS analysis and Annexin V staining assay also showed that both Saussurea lappa and Pharbitis nil induce apoptotic cell death of AGS. Expression analyses via RT-PCR and Western blots revealed that Saussurea lappa, but not Pharbitis nil, increased expression of the p53 and its downstream effector p2 $^{\text {Waf1 }}$, and that the both increased expression of apoptosis related Bax and cleavage of active caspase-3 protein. We also confirmed the translocation of Bax to mitochondria. Collectively, our data demonstrate that Saussurea lappa and Pharbitis nil induce growth inhibition and apoptosis of human gastric cancer cells, and these effects are correlated with down- and up-regulation of growth-regulating apoptotic and tumor suppressor genes, respectively.

Key words Saussurea lappa; Pharbitis nil; apoptosis; anti-tumor effect; Bax; medicinal herbs

Saussurea lappa, Pharbitis nil, Plantago asiatica, and Taraxacum mongolicum are representative anticancer medicinal herbs that have been traditionally used for cancer treatments in China, Japan and Korea. Previous studies also demonstrated that Saussurea lappa exhibits anti-tumor and anti-ulcer activity as well as anti-inflammatory effects via down-regulation of tumor necrosis factor- $\alpha,{ }^{1-5)}$ and that Pharbitis nil has the antifungal effects by antifungal peptides. ${ }^{6}$ Plantago asiatica and Taraxacum mongolicum have been widely used to treat for cancers and liver diseases and were reported to carry immune suppressive effects. ${ }^{7,8)}$

It is well known that tumor development is accelerated by disruption of the balance between cell proliferation and cell death, which is maintained through regulations of various signal transduction pathways. ${ }^{9,10)}$ Active cell death, known as apoptosis or programmed cell death, is caused by various physiologic and non-physiological cell injuries including DNA damage. It has been demonstrated that various cell proliferation- and apoptosis-signal transduction pathways are built on complicated networks between oncogenes and tumor suppressor genes such as p53 and its downstream factor p21. ${ }^{1-15)}$ For example, transcription and translation of antiapoptotic Bcl-2 and pro-apoptotic Bax are down- and up-regulated by $\mathrm{p} 53$, respectively. ${ }^{13)}$

p53 controls various genetic expressions and plays an important role in cell proliferation and in modulation of signal transduction pathways. Accumulation of p53 in cells after DNA damage leads to cell cycle arrest and apoptosis induction. In addition, p53 is involved in repair of damaged DNA and thus prevents accumulation of mutations and suppresses tumor development. ${ }^{16,17)}$
In our study, we analyzed effects of Saussurea lappa, Pharbitis nil, Plantago asiatica and Taraxacum mongolicum on proliferation and apoptosis of a human gastric cancer cell line AGS. Here we demonstrated first that Saussurea lappa and Pharbitis nil induced growth inhibition and apoptosis of AGS cells and these effects are correlated with down- and up-regulation of growth-regulating proapoptotic and tumor suppressor genes, respectively, suggesting that the anticancer effects of Saussurea lappa and Pharbitis nil might be associated with their regulatory capabilities of tumor-related genes expressions.

\section{MATERIALS AND METHODS}

Cell Culture The AGS human gastric carcinoma cell line was obtained from American Type Culture Collection (ATCC, Rockville, MD, U.S.A.) and grown in RPMI 1640 (Life Technologies, Inc., Rockville, MD, U.S.A.) containing 10\% FBS (Hyclone Laboratories, Inc., Logan, UT, U.S.A.) and $1 \%$ gentamicin in a $5 \% \mathrm{CO}_{2}$ humidified atmosphere. Subconfluent monolayers of cells were employed in all experiments.

Preparation of Medicinal Herbs The raw herbs were purchased from Omni-herb Inc. (Seoul, Korea) and extracted [Saussurea lappa (560 g), Pharbitis nil (570 g), Plantago asiatica $(550 \mathrm{~g})$ and Taraxacum mongolicum $(570 \mathrm{~g})]$ by sonication of dried roots of these plants in $80 \%$ ethanol, following by a freeze-drying process of the ethanol extract. Freeze dried powder forms of the extracts [Saussurea lappa (115.4 g), Pharbitis nil (14.8 g), Plantago asiatica (82.5 g) and Taraxacum mongolicum $(71.9 \mathrm{~g})]$ were dissolved in 
RPMI 1640 medium (Life Technologies, Inc.) to $10 \mathrm{mg} / \mathrm{ml}$, vortexed at room temperature for $1 \mathrm{~min}$, and incubated at $37^{\circ} \mathrm{C}$ for $1 \mathrm{~h}$ while rotating before use. These solutions were centrifuged at $12000 \mathrm{rpm}$ for $5 \mathrm{~min}$ to remove any insoluble ingredients. The supernatant was passed through a $0.22-\mu \mathrm{m}$ filter for sterilization and diluted with RPMI 1640 culture medium to final concentrations of $6.25-1000 \mu \mathrm{g} / \mathrm{ml}$.

Growth Inhibition Assay To determine the inhibition effect of these four herbal extracts on proliferation of AGS cells, the percentage of growth inhibition was determined by measuring MTT dye absorbance of viable cells in the absence or presence of medicinal herb extracts. Ten thousand cells per well were seeded onto a well of 96-well plates (Nunc, Roskilde, Denmark) for $24 \mathrm{~h}$, treated with various concentrations of these extracts, and incubated for $3 \mathrm{~d}$ at $37^{\circ} \mathrm{C}$. Subsequently, $50 \mu \mathrm{l}$ of MTT (Sigma) at a concentration of $2 \mathrm{mg} / \mathrm{ml}$ was added to each well, and cells were incubated for an additional $4 \mathrm{~h}$ at $37^{\circ} \mathrm{C}$. The supernatant was aspirated, and $150 \mu \mathrm{l}$ of DMSO were then added to the wells to dissolve any precipitate present. The absorbance was then measured at a wavelength of $570 \mathrm{~nm}$ using an ELX800 microplate reader (Bio-Tek Instruments, Inc., Winooski, VT, U.S.A.). The $\mathrm{IC}_{50}$ 's were calculated assuming the survival rate of untreated cells to be $100 \%$. To examine the time-dependent inhibition effects, cells were treated with Saussurea lappa and Pharbitis nil, which shown cytotoxic effects at the various times, cell viability was measured by a Trypan blue exclusion assay. To evaluate how much these herbal medicines have cytotoxic effects to cancer cells as compared with normal epithelial cell line, AGS and RIE1 cells, from rat intestine, were seeded to wells of 96 well plates in the presence of normal culture media at $1.0 \times 10^{4}$ cells/well. Twenty four hours later, cells were treated with indicated concentrations of Saussurea lappa and Pharbitis nil extracts for additional $72 \mathrm{~h}$. Then MTT assay was performed as explained in Material and methods. Data shown is representative from three independent experiments, in which each condition was in triplicate. Data were shown in mean \pm standard deviation (S.D.).

Flow Cytometric Cell Cycle or DNA Content Analysis A total of $5 \times 10^{5}$ cells were seeded in $60 \mathrm{~mm}$ dishes and incubated for $24 \mathrm{~h}$ at $37^{\circ} \mathrm{C}$. Saussurea lappa and Pharbitis nil extracts at indicated various concentrations was directly added to the dishes and incubated for an additional 12, 24, $48 \mathrm{~h}$. During harvests, both cells detached (probably apoptotic) and adherent were combined, fixed by addition of $4 \mathrm{ml}$ $70 \%$ ethanol, and stored at $-20^{\circ} \mathrm{C}$ at least $30 \mathrm{~min}$. Cells were then pelletted, washed twice with ice-cold PBS, incubated in PBS containing $10 \mu \mathrm{g} / \mathrm{ml}$ of RNase A (Sigma) for $15 \mathrm{~min}$ at $37^{\circ} \mathrm{C}$, and stained with $10 \mu \mathrm{g} / \mathrm{ml}$ of propidium iodide (PI). The relative DNA content per cell of samples was obtained by measuring the fluorescence of PI that bound stoichiometrically to DNA. The cell cycle was analyzed using a FACSCalibur flow cytometer (Becton Dickinson, San Jose, CA, U.S.A.) and a ModFit LT V2.0 computer program.

Apoptosis Assay To evaluate the apoptotic cell death, annexin $\mathrm{V}$ staining was carried out using an annexin $\mathrm{V}$ assay kit (PharMingen) according to the manufacture's recommendations. In brief, both floating and adherent cells were collected. Prepared cells were washed twice with ice-cold PBS and then resuspended in binding buffer $(10 \mathrm{~mm}$ HEPES/NaOH, pH 7.4, $140 \mathrm{~mm} \mathrm{NaCl,} 2.5 \mathrm{~mm} \mathrm{CaCl}_{2}$ ). Both
$5 \mu \mathrm{l}$ of annexin V-FITC and $10 \mu \mathrm{l}$ of $20 \mu \mathrm{g} / \mathrm{ml}$ PI were then added to these cells, which were later analyzed with a FACSCalibur flow cytometry (Becton Dickinson, San Jose, CA, U.S.A.).

DNA Fragmentation Assay Cells were collected, washed with PBS twice and then lysed in $100 \mu \mathrm{l}$ of lysis buffer (50 mm Tris ( $\mathrm{pH} 8.0), 10 \mathrm{~mm}$ EDTA, $0.5 \%$ sodium lauryl sarkosinate and $1 \mathrm{mg} / \mathrm{ml}$ protease $\mathrm{K}$ ) for $3 \mathrm{~h}$ at $56^{\circ} \mathrm{C}$ and treated with $0.5 \mathrm{mg} / \mathrm{ml}$ Rnase A for an additional $1 \mathrm{~h}$ at $56{ }^{\circ} \mathrm{C}$. DNA was extracted by the phenol/chloroform/isoamyl alcohol $(25 / 24 / 1)$ method before loading. Loading buffer $(50 \mathrm{~mm}$ Tris, $10 \mathrm{~mm}$ EDTA, $1 \%(\mathrm{w} / \mathrm{v})$ low melting point agarose, $0.25 \%(\mathrm{w} / \mathrm{v})$ bromophenol blue) and samples were loaded onto a presoldified, $2 \%(\mathrm{w} / \mathrm{v})$ agarose gel containing $0.1 \mu \mathrm{g} / \mathrm{ml}$ ethidium bromide. Agarose gels were electrophoresed at $50 \mathrm{~V}$ for $90 \mathrm{~min}$ in TBE buffer. Gels were observed and photographed under ultraviolet light.

Quantitative RT-PCR Analysis of Gene Expression Total cellular RNA was extracted from cultured cells by a single-step method. One microgram of extracted RNA was reverse-transcribed to cDNA in a $20 \mu \mathrm{l}$ reaction using MoMuLV (Gibco) and random hexamer primers. Two separate cDNAs were prepared from each RNA and diluted $1: 4$ or $1: 8$ with distilled, sterile $\mathrm{H}_{2} \mathrm{O}$ prior to PCR. For quantitative evaluation of gene expression, we initially performed PCR with exon-specific primer sets for all targets including a housekeeping standard GAPDH. The sequences of oligonucleotide primers will be provided upon request. PCR was performed with increasing cycle numbers $(21,24,27,30,33$, $36,39,42$ cycles) and diluted cDNAs (1:0,1:2, 1:4, 1:8). Each cycle comprised denaturation at $95^{\circ} \mathrm{C}$ for $1 \mathrm{~min}$, annealing at $58-62{ }^{\circ} \mathrm{C}$ for $1 \mathrm{~min}$, and polymerization at $72{ }^{\circ} \mathrm{C}$ for $1 \mathrm{~min}$. Ten microliters of the PCR products were resolved on 2\% agarose gels (FMC, Rockland, ME). Quantitative analysis of gene expression was confirmed through scanning of ethidium bromide-stained gels, using a laser densitometry. Measurement of signal intensity was performed using the Molecular Analyst program (version 2.0) on an IBM compatible computer.

Western Blot Analysis AGS cells in $100 \mathrm{~mm}$ dishes were treated with or without Saussurea lappa and Pharbitis nil extracts for indicated periods. After incubation, cells were washed with ice-cold PBS and lysates were prepared using a lysis buffer containing $20 \mathrm{~mm}$ Tris- $\mathrm{Cl}$ (pH 7.4), $100 \mathrm{~mm}$ $\mathrm{NaCl}, 1 \% \mathrm{NP} 40,0.5 \%$ sodium deoxycholate, $5 \mathrm{~mm} \mathrm{MgCl}_{2}$, $0.1 \mathrm{~mm}$ phenylmethylsulfonyl fluoride, $0.1 \mathrm{~mm}$ pepstatin A, $0.1 \mathrm{~mm}$ antipain, $0.1 \mathrm{~mm}$ chymostatin, $0.2 \mathrm{~mm}$ leupeptin, $10 \mu \mathrm{g} / \mathrm{ml}$ aprotinin, $0.5 \mathrm{mg} / \mathrm{ml}$ soybean trypsin inhibitor, and $1 \mathrm{~mm}$ benzamidine. After incubation of the lysates on ice for $30 \mathrm{~min}$, whole cell extracts were cleared by a centrifugation at $13000 \mathrm{rpm}$ for $20 \mathrm{~min}$. Twenty micrograms of protein were fractionated by SDS-PAGE denaturing gels and transferred onto a nitrocellulose membrane. The membrane was blocked for $1 \mathrm{~h}$ in the $20 \mathrm{~mm}$ Tris-buffered saline (TBS) buffer containing 5\% skim milk and $0.1 \%$ Tween 20 and then probed with specific antibodies for indicated molecules. The protein was detected using chemiluminescence method (Amersham Pharmacia Biotech) followed by autoradiography.

Subcellular Fractionation Cells were lysed in isotonic mitochondrial buffer in mitochondria lysis buffer $(210 \mathrm{~mm}$ sucrose, $70 \mathrm{~mm}$ mannitol, $10 \mathrm{~mm}$ Hepes, $\mathrm{pH}$ 7.4, $1 \mathrm{~mm}$ 
EDTA) containing $1 \mathrm{~mm}$ phenylmethylsulfonyl fluoride, $5 \mu \mathrm{g} / \mathrm{ml}$ leupeptin, $5 \mu \mathrm{g} / \mathrm{ml}$ aprotinin, and $0.7 \mu \mathrm{g} / \mathrm{ml}$ pepstatin. After homogenization with a Dounce homogenizer, cell lysates were centrifuged at $1000 \times \boldsymbol{g}$ for $10 \mathrm{~min}$ to discard nuclei and unbroken cells. The postnuclear supernatant was centrifuged at $10000 \times \boldsymbol{g}$ for $15 \mathrm{~min}$ to pellet mitochondriaenriched heavy membrane fraction, and the resulting supernatant was further centrifuged at $100000 \times \boldsymbol{g}$ for $30 \mathrm{~min}$ to obtain cytosolic fraction. The membrane fractions were resuspended in Triton X-100 lysis buffer containing protease inhibitors. Protein concentration was determined by BCA assay (Pierce Chemical, Rockford, IL, U.S.A.) and total proteins $(50 \mu \mathrm{g})$ from each fraction were subjected to immunoblot analysis.

Data Analysis Results shown are representative of at least three independent experiments performed in triplicate and are presented as the means \pm standard deviation (S.D.).

\section{RESULTS}

Growth Inhibition of AGS Gastric Cancer Cells by Saussurea lappa, Pharbitis nil, Plantago asiatica and Taraxacum mongolicum To determine treatment concentrations, we initially examined effects of four medicinal herbs on cell viability using MTT assay. The growth inhibition of AGS by the Saussurea lappa, Pharbitis nil, Plantago asiatica and Taraxacum mongolicum extracts were determined by quantifying viable cells in the absence or presence of treatment of each herbal extract at various concentrations for $3 \mathrm{~d}$. As shown in Fig. 1A, only Saussurea lappa and Pharbitis nil extracts significantly decreased cell viability in a dose-dependent manner. Based on the growth inhibition curves, the concentration of Saussurea lappa and Pharbitis nil extracts required for $50 \%$ inhibition of growth $\left(\mathrm{IC}_{50}\right)$ for AGS cells was about 100 and $12.5 \mu \mathrm{g} / \mathrm{ml}$. The maximal inhibition of cell growth $(>80 \%)$ were achieved at 200 and $60 \mu \mathrm{g} / \mathrm{ml}$ in AGS cells. A time-dependent growth inhibition of AGS cells by Saussurea lappa and Pharbitis nil extracts were also observed at the various times, and maximal growth inhibitions were shown within $2 \mathrm{~d}$ in Pharbitis nil extracts and within $4 \mathrm{~d}$ in Saussurea lappa extracts after the treatments (Fig. 1B). Meanwhile, the parallel treatment of the extracts to a normal epithelial cell line from rat intestine (RIE1) showed much less strong effects on inhibition of viability (with an $\mathrm{IC}_{50}$ at about 500 and $80 \mu \mathrm{g} / \mathrm{ml}$, respectively, Fig. 1C). Therefore, Saussurea lappa and Pharbitis nil extracts could induce growth inhibition of gastric cancer cells such as AGS cells.

Cell Cycle Analysis of Saussurea lappa and Pharbitis nil Based on the results from the preliminary study, two medicinal cytotoxic herbs, Saussurea lappa and Pharbitis nil extracts were chosen to examine their cytotoxic effects. To further characterize whether these herbs affect apoptotic population after the treatments, cells were treated with 100 and $12.5 \mu \mathrm{g} / \mathrm{ml}$ concentrations, respectively, for 12 to $48 \mathrm{~h}$, before flow cytometry analyses. While no detectable changes in cell cycle distribution were observed until $48 \mathrm{~h}$ after treatment, significant increases of cell population with subG1 DNA content, as time passed after treatment of Saussurea lappa and Pharbitis nil extracts were found at 24, and $48 \mathrm{~h}$ (Figs. 2A, B). However, cells in control condition showed no significant apoptotic population.
(A)

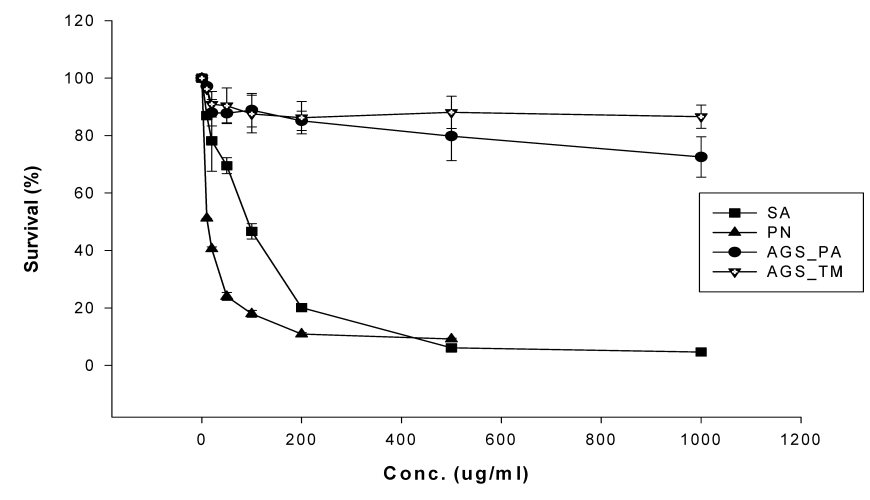

(B)

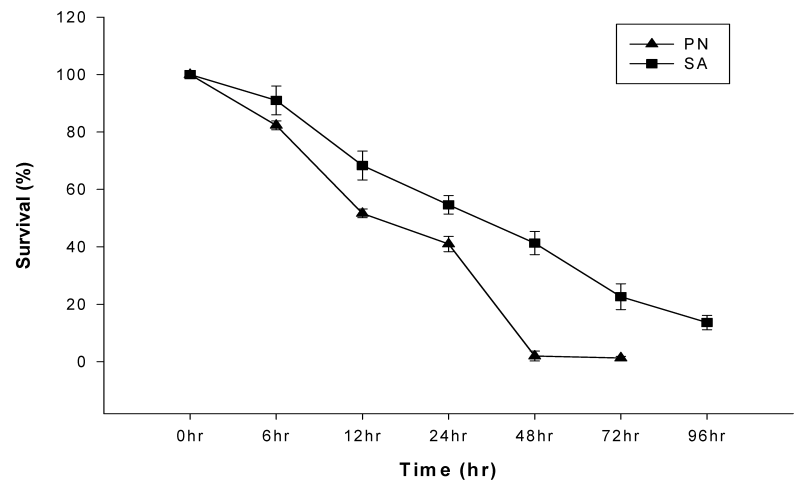

(C)

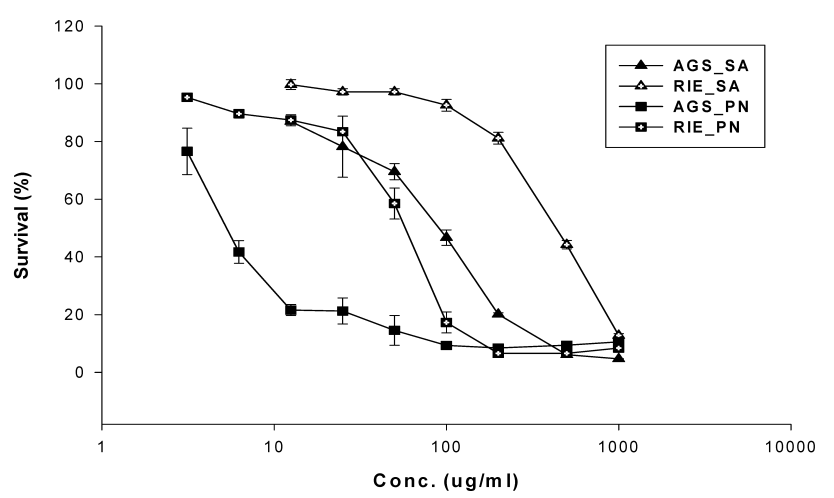

Fig. 1. Medicinal Herb-Mediated Inhibition of Cell Viability in Gastric AGS Cells

(A) Inhibition of cellular growth by four medicinal herbs in a dose-dependent manner. AGS cells seeded to wells of 96 well plates in the presence of normal serum containing media at $1.0 \times 10^{4}$ cells/well. Twenty four hours later, cells were treated with indicated concentrations of four medicinal herbal extracts for further $72 \mathrm{~h}$. Then MTT assay was performed as explained in Material and Methods. (B) Inhibition of cellular growth by four medicinal herbs in a time-dependent manner. AGS cells seeded to $60 \mathrm{~mm}$ culture dishes in the presence of normal serum containing media at $5 \times 10^{5}$ cells/dish. Twenty four hours later, cells were treated with 100 and $12.5 \mu \mathrm{g} / \mathrm{ml}$ of Saussurea lappa and Pharbitis nil extracts for the indicated time. Then Trypan blue exclusion assay was performed and viable cell counted. (C) Inhibition of AGS cell growth by the Saussurea lappa and Pharbitis nil extracts. AGS or RIE1 cells were seeded to wells of 96 well plates in the presence of normal culture media at $1.0 \times 10^{4}$ cells/well. Twenty four hours later, cells were treated with indicated concentrations of Saussurea lappa and Pharbitis nil extracts for additional $72 \mathrm{~h}$. Then MTT assay was performed as explained in Materials and Methods. Data shown is representative from three independent experiments. SA, Saussurea lappa; PN, Pharbitis nil; PA, Plantago asiatica; TM, Taraxacum mongolicum.

Annexin V Staining Assay and DNA Fragmentation Assay of Saussurea lappa and Pharbitis nil Next we tried to determine if Saussurea lappa and Pharbitis nil extracts in- 
(A)
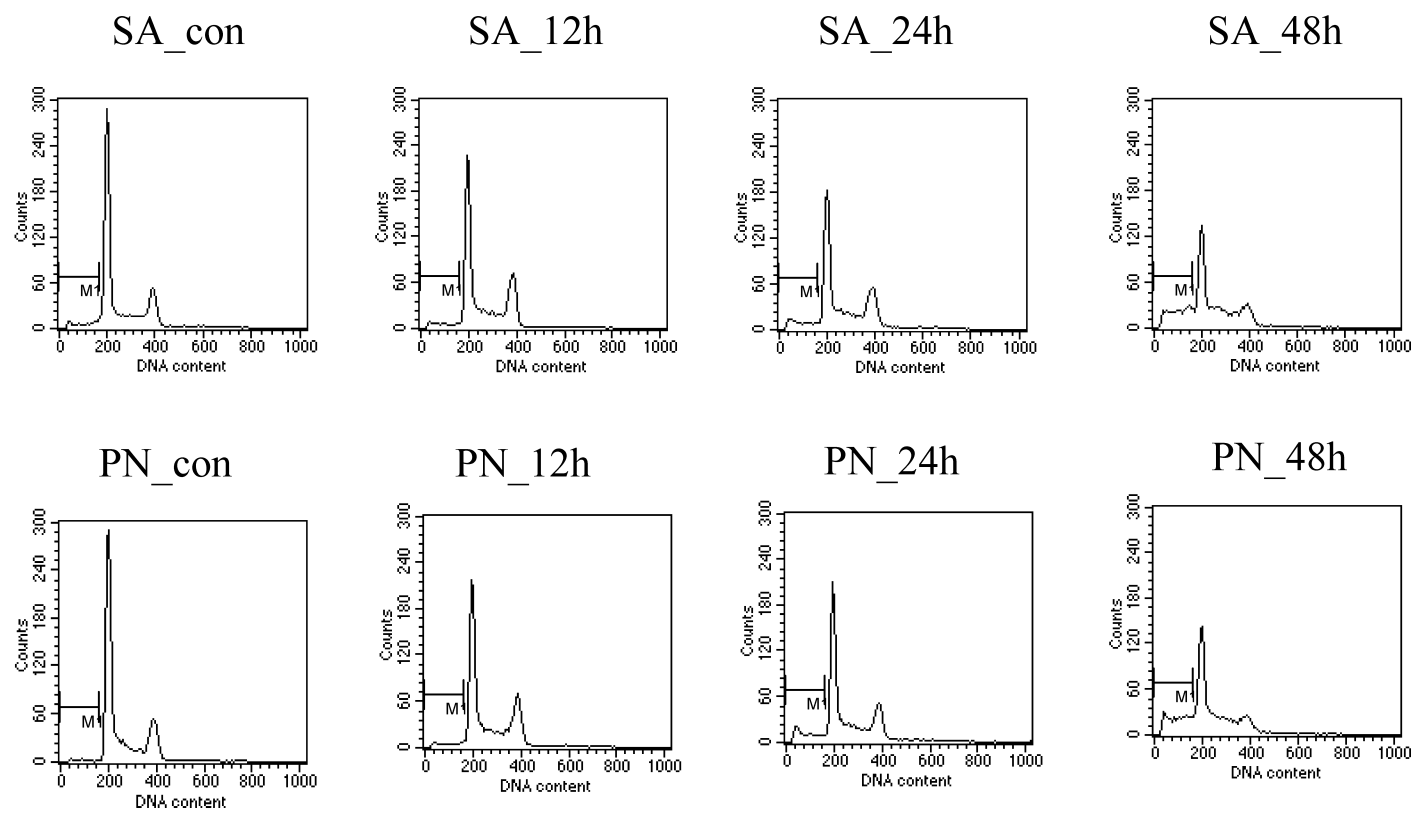

(B)

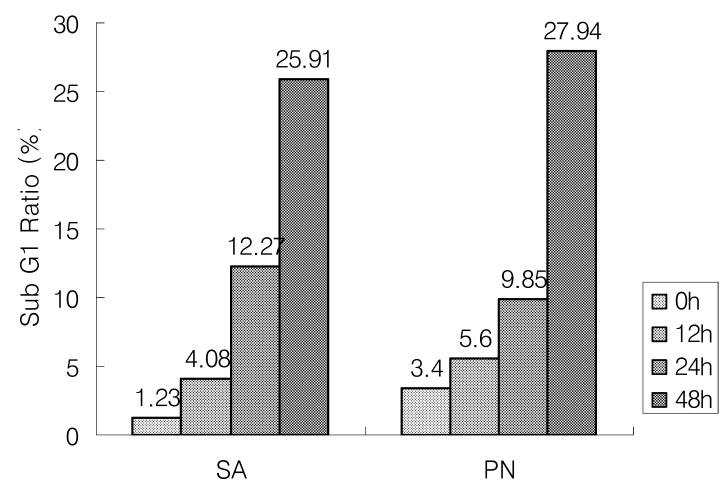

Fig. 2. Treatment of Saussurea lappa and Pharbitis nil Extracts Induced Apoptosis

(A) Saussurea lappa and Pharbitis nil extracts induced apoptosis. Cells in $60 \mathrm{~mm}$ culture dishes were treated with Saussurea lappa and Pharbitis nil extracts at 100 and $12.5 \mu \mathrm{g} / \mathrm{ml}$ for indicated periods. The treatments were done by a direct addition of Saussurea lappa and Pharbitis nil extracts solution into culture media. The solution was made of RPMI1640 culture media as explained in the Materials and Methods. After incubation, cells floating and adherent were harvested and combined before PI staining and flow cytometric analysis for subG1 population and cell cycle as explained in the Materials and Methods. (B) Apoptotic population by the treatments of Saussurea lappa and Pharbitis nil were shown with histogram. SA, Saussurea lappa; PN, Pharbitis nil.

duced apoptotic cell death of AGS cells. As shown in Figs. $2 \mathrm{~A}$ and $\mathrm{B}$, untreated cells did not show any significant apoptosis, whereas cells were becoming rapidly apoptotic with time after treatment with the extract. In addition to flow cytometric cell cycle analysis, we performed another approach to detect apoptotic cells using annexin V staining. In this assay, Saussurea lappa and Pharbitis nil extracts showed apoptotic populations of about $13.75 \%$ and $17.15 \%$, respectively, when cells were treated with 100 and $12.5 \mu \mathrm{g} / \mathrm{ml}$ Saussurea lappa and Pharbitis nil extracts for $24 \mathrm{~h}$. To demonstrate apoptotic cell death by Saussurea lappa and Pharbitis nil extracts, we also examined DNA fragmentation assay, and in this study, we got the evidence of DNA fragmentation of morphological changes of nuclei in AGS gastric cells.

Transcriptional Up-Regulation of the Tumor Suppressor Genes p53 and p21 ${ }^{\text {Wafl }}$ Expression We next examined, using semi-quantitative RT-PCR assay, the possibility that growth inhibition and apoptosis induction by Saussurea lappa and Pharbitis nil were associated with their regulatory effects on the cell cycle- and apoptosis-controlling genes expressions. As shown in Fig. 4, treatment of Saussurea lappa resulted in increase of transcription of the p53 tumor suppressor gene and its downstream effector $\mathrm{p} 21^{\text {Wafl }}$ at $48 \mathrm{~h}$ after the treatment. In contrast to Saussurea lappa, Pharbitis nil also showed a strong growth arrest and apoptosis induction activity, but did not increase $\mathrm{p} 53$ and $\mathrm{p} 21^{\text {Wafl }}$ expression. We also analyzed mRNA expression of p16 ${ }^{\text {Ink4A }}$, another tumor suppressor gene which also plays a critical role in regulation of cell cycle progression and apoptosis, but its expression was not modulated by any of the two herbal medicines tested. Next, we examined expression of representative anti-apoptotic genes, such as Bcl-2 and Bcl- $\mathrm{X}_{\mathrm{L}}$, and a pro-apoptotic gene Bax. Whereas no effects on Bcl-2 and Bcl- $\mathrm{X}_{\mathrm{L}}$ expression were observed, Saussurea lappa and Pharbitis nil 


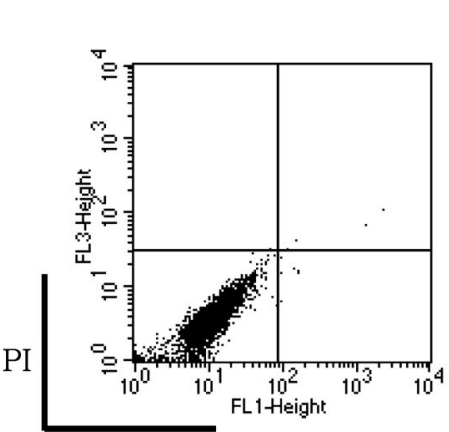

Annexin V-FITC
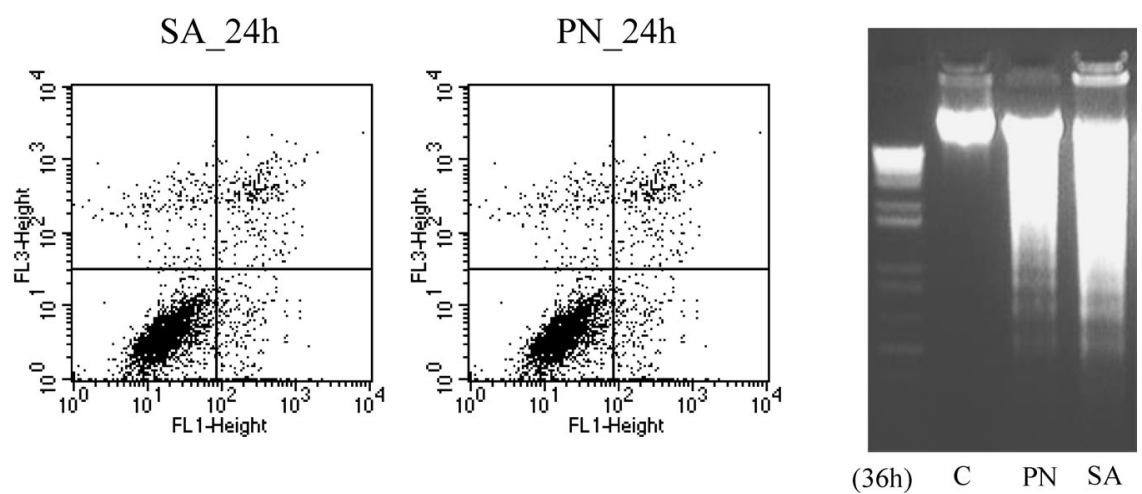

Fig. 3. The Externalization of Phophatidylserine during Saussurea lappa and Pharbitis nil-Induced Apoptosis

(A) Annexin V staining combined with PI staining was performed in control cells (left histogram) and cells treated with $100 \mu \mathrm{g} / \mathrm{ml}$ of Saussurea lappa (2nd histogram) and $12.5 \mu \mathrm{g} / \mathrm{ml}$ of Pharbitis nil (3rd histogram) extracts for the $24 \mathrm{~h}$ and then analyzed by flow cytometry. Early apoptotic cells were localized in the lower right quadrant of a dot-plot graph using Annexin V FITC versus PI. (B) DNA fragmentation assay was examined to confirm of late apoptotic change of nuclei after treatment of Saussurea lappa and Pharbitis nil extracts, 100 and $12.5 \mu \mathrm{g} / \mathrm{ml}$, respectively, for $36 \mathrm{~h}$.

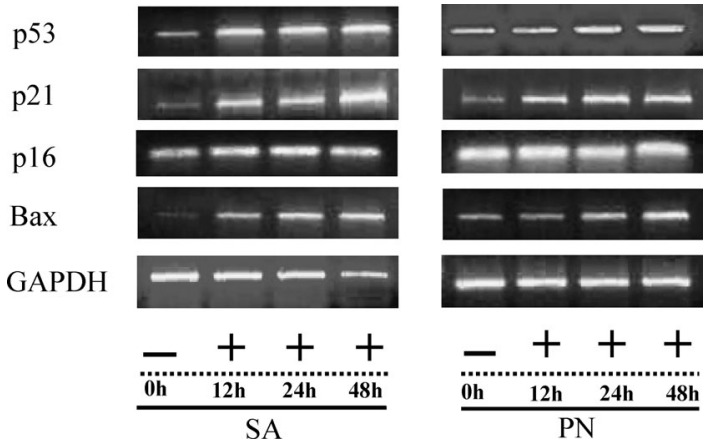

Fig. 4. A Semi-quantitative RT-PCR Analysis for Cell Cycle- and Apoptosis-Related Gene Expression

One microgram of total cellular RNA extracted from untreated and treated AGS cells was converted to cDNA by reverse transcription and $1: 4$ diluted cDNA was subjected to PCR amplification of $\mathrm{p} 53$, p $21^{\text {Waf1 }}, \mathrm{p} 16^{\text {Ink4A }}$, Bax and an internal control gene, GAPDH. Ten microliters of PCR products was resolved on a $2 \%$ agarose gel and its band intensities were scanned using a densitometry.

showed a strong stimulating effect on Bax gene expression. Induction of the Bax gene transcription by either Saussurea lappa and Pharbitis nil was dependent on the treatment time. A representative example of gene expression analysis was shown in Fig. 4.

Western Blot Analysis Based on the apoptotic analysis by determination of cells with subG1 DNA contents and RTPCR analysis on cell cycle arrest- and apoptosis-related genes transcriptions, we have then examined expression levels of cell apoptotic molecules. In this analysis, we have confirmed intracellular apoptotic events biochemically, by examining the expression levels of pro-apoptotic molecules such as active caspase 3, and Bax, and an anti-apoptotic molecule of $\mathrm{Bcl}_{2}$. Cell lysates were prepared at various time points after treatment of Saussurea lappa and Pharbitis nil extracts, and used for Western blots. As shown in the Fig. 5, the level of anti-apoptotic $\mathrm{Bcl}_{2}$ was not altered significantly by the both herbal extract treatments, but the expression of proapoptotic Bax increased gradually with the treatment. Inductions of p53 and its downstream targets including Bax and $\mathrm{p} 21^{\text {Waf1 }}$ were obvious in case of treatment of Saussurea lappa, indicating that the apoptotic effects of the extract
(A)

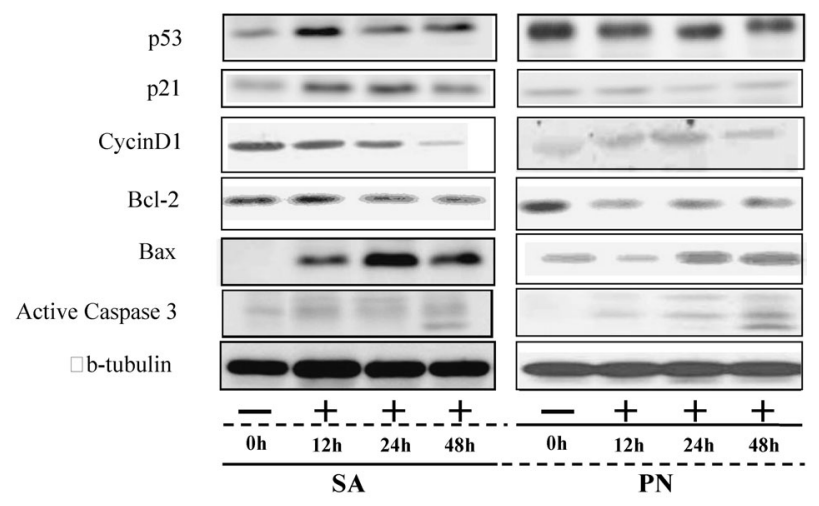

(B)

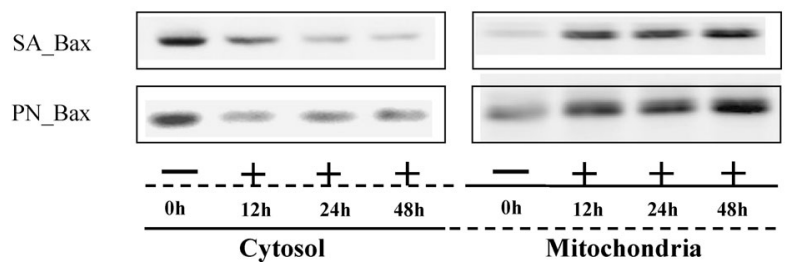

Fig. 5. Treatment of Saussurea lappa and Pharbitis nil Extracts Regulates Apoptotic Related and Cell Cycle Related Expression Levels

(A) Cells in $100 \mathrm{~mm}$ culture dishes were treated with Saussurea lappa and Pharbitis nil extracts at 100 and $12.5 \mu \mathrm{g} / \mathrm{ml}$ for indicated periods. After treatment, cells were washed twice with ice-cold PBS and then lysates were prepared using a RIPA lysis buffer. Lysates normalized to have equal protein amounts were used immunoblots by SDS-PAGE using primary antibodies against indicated molecules, as described in the Materials and Methods. (B) Cells were lysed in isotonic mitochondrial buffer in mitochondria lysis buffer containing protease inhibitor. After homogenization, cell lysates were centrifuged at $1000 \times \boldsymbol{g}$. The postnuclear supernatant was centrifuged at $10000 \times \boldsymbol{g}$ and the resulting supernatant was further centrifuged at $100000 \times \boldsymbol{g}$ to obtain cytosolic fraction. The membrane fractions were resuspended in Triton X-100 lysis buffer containing protease inhibitors. Total proteins $(50 \mu \mathrm{g})$ from each fraction were subjected to immunoblot analysis.

might involve p53 action to induce Bax (leading to apoptosis) and $\mathrm{p} 21^{\text {Wafl }}$, and furthermore activation of caspase 3, whereas in case of Pharbitis nil treatment activation of cas- 
pase 3 appeared to be involved (Fig. 5A). It is well known that apoptotic stimuli trigger Bax translocation to mitochondria where active Bax causes subsequent activation of certain downstream effector caspases 3 and its substrate PAPR cleavage. To examine Bax activation in response to Saussurea lappa and Pharbitis nil extracts treatment, we performed subcellular fragmentation assay that recognizes the translocation of Bax protein. In this subcellular fractionation/immunoblot analysis confirmed Bax translocation to mitochondria in AGS cells treated with Saussurea lappa and Pharbitis nil extracts (Fig. 5B).

Taken together, apoptosis by the treatments of Saussurea lappa and Pharbitis nil might be caused by their abilities in regulations of expression levels of growth arrest and apoptosis-related genes.

\section{DISCUSSION}

Conventional medicines have usually sorted to a number of treatments such as operation, radiotherapy, and chemotherapy. The existing anti-cancer agents, designed to eradicate cancer cells, have strong toxicities, also with leading to harmful side effects. Recently, a number of researches on natural products have been actively carried out in efforts to develop new treatments that can decrease side effects or increase anti-cancer effects.

Saussurea lappa, Pharbitis nil, Plantago asiatica, and Taraxacum mongolicum are representative herbal medicines that have traditionally been used for cancer treatments in East Asia, such as China, Japan and Korea. ${ }^{1,7,18)}$ Several previous studies have demonstrated that these herbs exhibited anti-tumor activities. ${ }^{1-5)}$

In the present study, we analyzed effects of Saussurea lappa, Pharbitis nil, Plantago asiatica and Taraxacum mongolicum on proliferation and apoptosis of a human gastric cancer cell line AGS. Our cell proliferation assay showed that Saussurea lappa and Pharbitis nil strongly inhibited cell proliferation of AGS, whereas Plantago asiatica and Taraxacum mongolicum exhibited no detectable effects on cellular growth (Fig. 1A). Saussurea lappa and Pharbitis nil also showed the inhibition effects of cellular proliferation in timedependent manner and cancer cell specific cytotoxic effects (Figs. 1B, C). Based on the results of cytotoxicities of the two medicinal herbs (i.e., Saussurea lappa and Pharbitis nil), we have done further studies.

In the cell cycle analysis of our study, Saussurea lappa and Pharbitis nil extracts showed no detectable changes in cell cycle distribution after treatment, but significant increases of cell population with subG1 DNA content were observed at 24, and $48 \mathrm{~h}$ (Figs. 2A, B). In the annexin V staining, Saussurea lappa and Pharbitis nil extracts also showed apoptotic changes in AGS cell lines. We also performed DNA fragmentation assay, DNA fragmentation which means late marker of apoptosis, in this assay, after treatment of Saussurea lappa and Pharbitis nil extracts for $36 \mathrm{~h}$, significant DNA fragmentations were detected in both medicinal herbs (Figs. 3A, B).

Being consistently, in our semi-quantitative RT-PCR analysis, the increases of mRNA expression levels of p53 tumor suppressor and its downstream effector $\mathrm{p} 21^{\text {Wafl }}$ were detected only in case of Saussurea lappa treatment, which means that growth inhibition and apoptosis induction by Saussurea lappa are associated with its regulatory effect on the cell cycle- and apoptosis-controlling genes expressions, but Pharbitis nil did not altered the levels of p53 and p21 expression. Saussurea lappa and Pharbitis nil also showed a strong stimulating effect on transcription and induction of expression of Bax.

Apoptosis is a genetically programmed event that can take place by a variety of internal or external stimuli and these signals are regulated by two distinct pathways, involving either death receptor (extrinsic) or mitochondria. ${ }^{19,20)}$ In the mitochondrial pathway, a variety of death signals triggers the release of several pro-apoptotic proteins, in these proteins Bax is a crucial mediator of the mitochondrial pathway for apoptosis, and loss of this proapoptotic Bcl-2 family protein contributes to drug resistance in human cancers. ${ }^{21)}$ Previous studies have shown that tumor cells with mutational inactivation of apoptosis-inducing genes, such as a tumor-suppressor gene $\mathrm{p} 53$, failed to respond to chemotherapeutic agent-induced DNA damage, and that a number of apoptosis-related genes such as Bcl-2 family members display both pro-survival and pro-apoptotic functions by forming homodimers or heterodimers. ${ }^{22}$ Bax, a tumor suppressor, mediates the p53induced apoptosis and it increases sensitivity to chemotherapy-induced apoptosis. ${ }^{23-25)}$ Meanwhile when Bcl-2 is activated or prevalent, apoptosis is prohibited. Abnormal overexpression of Bcl-2 has frequently been observed in many types of human cancers, and relative expression levels of Bcl-2 to Bax were reported to determine the sensitivity to apoptosis. $^{26-28)}$ In addition, p53's DNA binding property and its ability of controlling gene transcription and transduction are usually lost by mutation in human cancers and $\mathrm{p} 21^{\text {Waf1 }}$ gene is highly activated by $\mathrm{p} 53$, and $\mathrm{p} 53$-induced $\mathrm{p} 21^{\text {Wafl }}$ leads to arrest of the cell cycle and/or apoptosis. ${ }^{20}$

According to our apoptotic analysis by determination of cells with subG1 DNA contents, annexin V staining and RTPCR analysis, it is likely that the growth inhibition by Saussurea lappa and Pharbitis nil extracts might involve apoptosis. When we also analyzed cyclinD1 levels after the treatments, growth inhibition by Saussurea lappa, but not Pharbitis nil, was observed, indicating differential mechanisms underlying for the cytotoxicities by either Saussurea lappa or Pharbitis nil. We have confirmed the idea by analyzing intracellular events biochemically, such as the expression of a pro-apoptotic molecule, Bax, and anti-apoptotic molecules including Bcl2 and cleavage of active caspase 3 and also got evidence of Bax protein translocation to mitochondria by subcellular fragmentation.

Collectively, in this subcellular fractionation/immunoblot analysis confirmed that cytotoxic effects of Saussurea lappa and Pharbitis nil extracts in AGS cells were mediated by mitochondrial apoptotic pathway. And our observations thus suggests that anticancer effect of Saussurea lappa and Pharbitis nil might be associated with their ability to regulate tumor-related genes expressions.

Acknowledgements This study was supported by a grant of Bureau of Oriental Medicine Policy, Ministry of Health and Welfare, Republic of Korea and Sangji University of Korea. 


\section{REFERENCES}

1) Jung J. H., Kim Y., Lee C. O., Kang S. S., Park J. H., Im K. S., Arch. Pharm. Res., 21, 153-156 (1998).

2) Cho J. Y., Baik K. U., Jung J. H., Park M. H., Eur. J. Pharmacol., 398 399-407 (2000).

3) Cho J. Y., Park J., Yoo E. S., Baik K. U., Jung J. H., Lee J., Park M. H., Planta Med., 64, 594-597 (1998).

4) Yoshikawa M., Hatakeyama S., Inoue Y., Yamahara J., Chem. Pharm. Bull., 41, 214-216 (1993).

5) Robles M., Aregullin M., West J., Rodriguez E., Planta Med., 61, 199-203 (1995).

6) Koo J. C., Lee S. Y., Chun H. J., Cheong Y. H., Choi J. S., Kawabata S., Miyagi M., Tsunasawa S., Ha K. S., Bae D. W., Han C. D., Lee B. L., Cho M. J., Biochim. Biophys. Acta, 15, 80-90 (1998).

7) Kim S. H., J. Kor. Ori. Med., 19, 470-499 (1998).

8) Yamada H., Nagai T., Takemoto N., Endoh H., Kiyohara H., Kawamura H., Otsuka Y., Biochem. Biophys. Res. Commun., 165, 12921298 (1989).

9) Collins M. K. L., Rivas A. L., Trends Cell Biology, 18, 307-309 (1993).

10) Williams G. T., Smith C. A., Cell, 74, 777-779 (1993).

11) Levine A. J., Cancer Surv., 12, 59-79 (1992).

12) Lane D. P., Nature (London), 358, 15-16 (1992).

13) Miyashita T., Harigai M., Hanada M., Reed J. C., Cancer Res., 54, 3131-3135 (1994).

14) Yonish-Rouach E., Resnitzky D., Lotem J., Sachs L., Kimchi A., Oren
M., 352, Nature (London), 345-347 (1991).

15) Wang E., Lee M. J., Pandey S., J. Cell Biochem., 54, 432- 439 (1994).

16) Kastan M. B., Zhan Q., El-Deiry W. S., Carrier F., Jacks T., Walsh W. V., Plunkett B. S., Fornace A. J., Cell, 71, 587—597 (1992).

17) Ginsberg D., Mechta F., Yaniv M., Oren M., Proc. Natl. Acad. Sci. U.S.A., 88, 9979-9983 (1991).

18) Kim D. H., Kim S. H., J. Kor. Ori. Med., 16, 386-413 (1995).

19) Reed J. C., Trends Mol. Med., 7, 314-319 (2001).

20) Wyllie A. H., Br. J. Cancer, 67, 205-208 (1994).

21) Yamaguchi H., Bhalla K., Wang H. G., Cancer Res., 63, 1483-1489 (2003).

22) Findly H. W., Gu L., Yeager A. M., Zhou M., Blood, 89, 2986-2993 (1997).

23) Schlesinger P. H., Gross A., Yin A. M., Yamanoto K., Saito M., Waksman G., Korsmeyer S. J., Proc. Natl. Acad. Sci. U.S.A., 94, 1135711362 (1997)

24) Tu Y., Feng-hao Xu, Jin Liu, Versco R., Berenson J., Fady C., Lichtanstein A., Blood, 88, 1805-1812 (1996).

25) Lisovsky M., Estrov Z., Zhang X., Consoli U., Sanchez-Williams G., Snell V., Munker R., Goodacre A., Mack D. H., Vartikar J., Pipas J. M., Laimins L. A., Nature (London), 363, 281-283 (1993).

26) Itoh N., Tsujimoto Y., Nagata S., J. Immunology, 151, 621-627 (1993).

27) Strobel T., Swanson L., Korsmeter S., Cannistra S. A., Proc. Natl. Acad. Sci. U.S.A., 93, 14094-14099 (1996).

28) Yin C., Knudson C. M., Korsmeyer S. J., Van-Dyke T., Nature (London), 385, 637—640 (1997). 